\title{
Parental Occupation and Mental Health of Young Adults
}

\author{
Ruchi Singh and Ragini Mishra \\ Dept. of Human Development and family studies, College of Home science, GBPUAT, \\ Pantnagar, Uttarakhnad, India \\ *Corresponding author
}

\section{A B S T R A C T}

\section{Keywords}

Young adults, Mental health, Parental occupation, Housewife, Farmer, Government job

Article Info

\section{Accepted:}

17 January 2021

Available Online:

10 February 2021
Occupation is the defining activity in people's lives and parental occupation always has significant impact on lives of their children. The proposed research was subsequently expected to test the mental health status of young adults with regard to their parental occupation. 240 students were selected through simple random sampling method from colleges of G.B. Pant University of Agriculture and Technology. A tool namely MHBMental Health Battery (Physiological Health, Daily Routine Activity, Emotional Status, Emotional Management and Intelligence) was developed. To establish the content validity, Mental Health Battery was evaluated by to subject experts and thereafter reliability of the tool was calculated through pilot study. Frequency, percentage, $\mathrm{p}$ value and correlation were calculated to derive the research results. The finding of research suggests a significant association was found between mental health of young adults and parental occupation.

\section{Introduction}

Occupation or job is one's role in society, often a regular activity performed for payment or earning. Occupation is the defining activity in people's lives (Wikipedia). There is no one answer to whether it is good if both parents are working. Since women began entering the workforce in increasing numbers in the late 20th century, psychologists and child development experts have questioned the effects of working parents on a child's overall development. Many families must rely on financial support from both parents, thus necessitating the dualincome family, but healthy social and emotional development depends on more than just the amount of time spent with children (WOW Parenting, 2019).

Parents are the first teachers in a child's life and play a pivotal role in shaping their adult 
lives (Nair, 2018). Earlier, when there was a joint family system, raising a child was not a difficult task; as there were multiple caretakers apart from the mother. Aunts, uncles, and grandparents, everybody helped in raising the kids in the family. Since recent times, with the increasing trend of the nuclear families emerging in the country, the working class parents had no other option but to leave their kids alone. The effects of both parents working have their own pros and cons. In most of the world, it is a matter of survival, but work also places people in stratification systems, shapes their physical and emotional well-being, and influences their chances for social mobility. Working parents are an inevitable trend and have their own share of advantages and disadvantages.

Parents are among the most important people in the lives of young children. From birth, children are learning and rely on mothers and fathers, as well as other caregivers acting in the parenting role, to protect and care for them and to chart a trajectory that promotes their overall well-being. While parents generally are filled with anticipation about their children's unfolding personalities, many also lack knowledge about how best to provide for them. Becoming a parent is usually a welcomed event, but in some cases, parents' lives are fraught with problems and uncertainty regarding their ability to ensure their child's physical, emotional, or economic well-being (National Academic Press, 2016). Mental health research demonstrates that a kind of occupation a family does has a lasting influence their mental health and wellbeing. If we talk about the young adult, there is definite impact of their parental occupation/work on their mental health status because parental occupation not only help children by providing financial support also affects their educational and career choices along with their mental health. Therefore, this part focuses on relationship between kind of occupation of parents and mental health of young adults.

\section{Materials and Methods}

A total Number of 240 students were selected through simple random sampling method from colleges of G.B. Pant University of Agriculture and Technology. A tool namely MHB-Mental Health Battery (Physiological Health, Daily Routine Activity, Emotional Status, Emotional Management and Intelligence) was developed (Singh \& Mishra, 2020). To establish the content validity (Mishra \& Gir, 2013, 2014), Mental Health Battery was evaluated by to subject experts and thereafter reliability of the tool was calculated through pilot study (Mishra \& Gir, 2013, 2014). Frequency, percentage, p value and correlation were calculated to derive the research results. The finding of research suggests a significant association was found between mental health of young adults and parental occupation.

\section{Results and Discussion}

\section{Mental health of young adults with respect to their parental occupation}

Occupation is the defining activity in people's lives. In most of the world, it is a matter of survival, but work also places people in stratification systems, shapes their physical and emotional well-being. Table 1 discussed about the impact of parental occupation on mental health of young adults. It was found in table 1 that majority of young adult belonging to the fathers working as a farmer (64.20\%), employed in government $(62.70 \%)$ and private jobs $(56.70 \%)$ portrayed poor mental health while young adults belonging to the homemaker mothers $(64.20 \%)$ were found with poor mental health. Table 1 reflects that young adult belonging to the fathers working in private jobs $(73.90 \%)$, government jobs 
$(65.80 \%)$ and farmers $(64.20 \%)$ displayed poor physiological health. The table also shows that majority of young adult belonging to the mothers working in private $(81.20 \%)$ and government jobs $(64.20 \%)$ or were homemakers $(67.30 \%)$ also portrayed poor physiological health. it is observed that parental support is an important factor for young people to perceive themselves as important and valuable. Mothers who do not work can spend more time with their children at home and work closely with them. Similar findings were obtained in a study and it was found that the adolescents who were next to the family were more hopeful (Lok et al. 2017).

Table 1 reflects that young adult belonging to the parents (mother and father) employed in government sector $(55.90 \%$ and $71.50 \%$ respectively) had an average impact on their daily routine activity whereas young adult belonging to the parents (mother and father) employed in private sector $(52.10 \%$ and $50 \%$ respectively) were found with poorly affected daily routine life. Table also reveals that young adult belonging to the farmer fathers (50\%) and homemakers' mothers (50\%) also portrayed highly affected daily routine activity.

The results of table 1 reflects that young adults belonging farmer fathers $(83.40 \%)$ and fathers with private $(76.80 \%)$ and government jobs $(62 \%)$ reflected average effect on their emotional status. Similar results were found in case of young adults belonging to the mothers working in government $(75 \%)$ and private sectors $(56.20 \%)$ or were homemakers (70.90.). Emotional stress, the aspect of emotional status shows that young adult belonging to the father working in private $(75.40 \%)$ and government sector $(55.90 \%)$, and doing farming $(71.40 \%)$ portrayed average emotional stress. Similar results found in young adult belonging to the working mothers i.e. government jobs
$(67.80 \%)$, homemakers $(64.80 \%)$ and private jobs $(50 \%)$ respectively who also portrayed average emotional stress condition. Table 1 reveals that young adults with fathers working as farmer (100\%), doing government $(68.30 \%)$ and private jobs $(87 \%)$ portrayed average sense of self. In case of young adults with working mothers average sense of self and no young adults was having good sense of self where it compared to parental occupation. Table 1 reveals that young adults with fathers doing government jobs (68.20\%), private jobs $(60.90 \%)$ and working as farmer $(60.90 \%)$ portrayed average sense of conflictlessness. In case of young adults with working mothers' average sense of conflictlessness and less young adults was having good sense of conflictlessness where it compared to parental occupation. Children whose parents do not fulfil either of these roles, even though they are physically present, can experience severe emotional conflicts. The effects of absent parents on a child often leave him unable to form healthy relationships, or he may have stress related illnesses due to the unresolved conflicts of his childhood. Mohsene (2019) says that many adults still struggle with the emotional turmoil they experienced in childhood caused by parents who were physically or emotionally absent Poor-quality day care services can hamper a child's emotional and social development. Under-qualified and overburdened staff and poor facilities at the daycare can affect your child's physical and psychological health. Mothers might feel over-burdened and weary of trying to balance work and family. If mothers bring their frustration home, children could develop a negative attitude. They could perceive her work as a source of distress for their family. Mothers, in spite of having their kid's best interests at heart, might fail to provide their children a safe emotional outlet. They might not be enthusiastic to hear their children' issues after a hectic day at work. 
Table.1 Mental Health of young adults with respect to their parental occupation

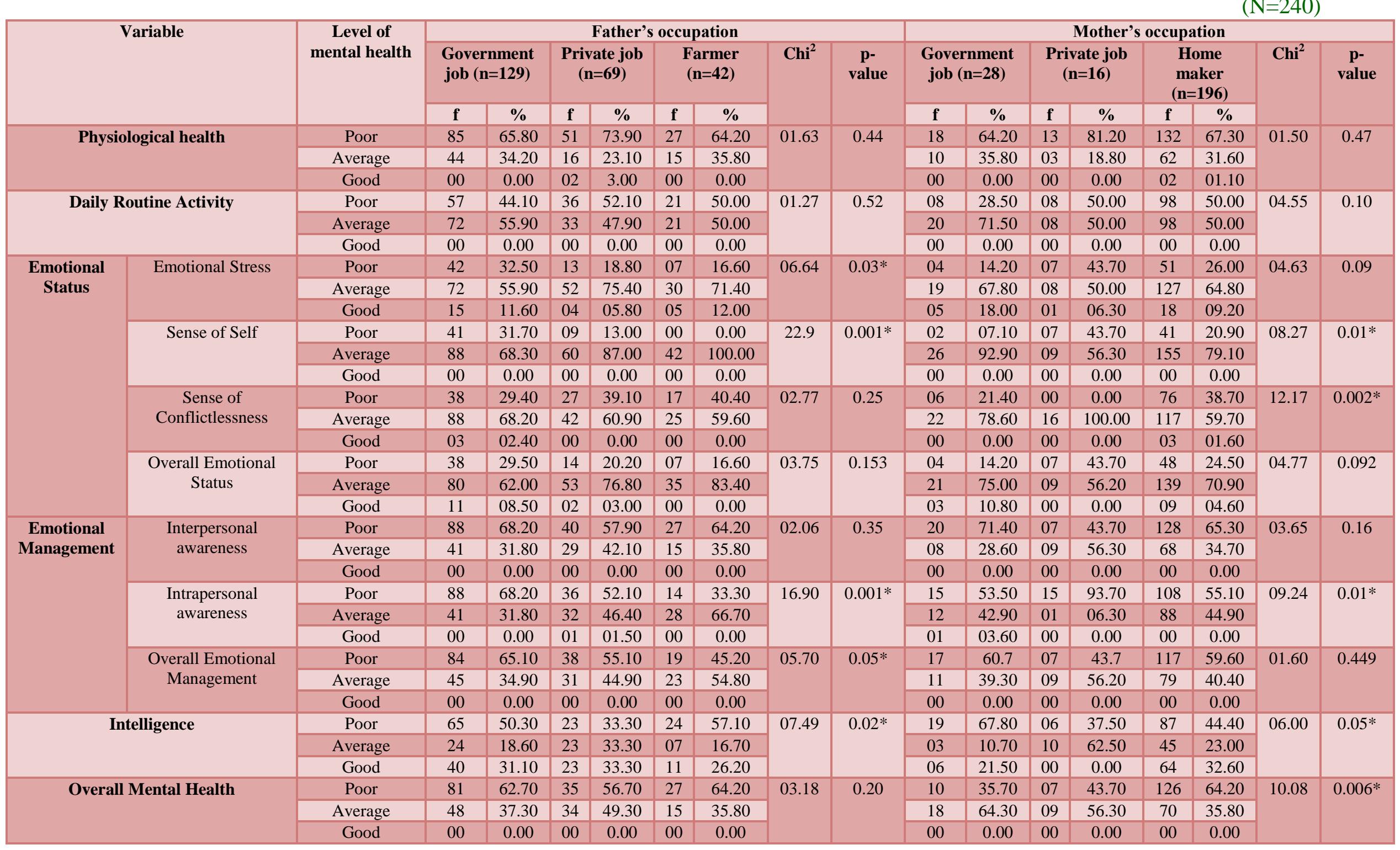


Children in such cases could resort to finding an outlet elsewhere or simply feel that their parents are not interested in their lives. Problems can arise between parents over the mother's employment. Such parental conflict can adversely affect children. It could damage their self-esteem and make them insecure. The mother who is stayed at home and unhappy about her situation cannot be an ideal mother (Singh, 2018). Lifetime risk of affective disorders, panic disorders, generalized anxiety disorder, specific phobia and substance use disorders is found to be highest among unemployed persons (Deswal and Pawar, 2012).

Table 1 reflects that young adult belonging to the father employed in government $(65.10 \%)$ and private sector $(55.10 \%)$ portrayed poor emotional management while young adults with father doing farming $(54.80 \%)$ portrayed average capabilities of managing their emotion. In case of young adult belonging to the mothers employed in government sector $(60.70 \%)$ and housewives $(59.60 \%)$ portrayed poor emotional management while young adult belonging to mother doing private jobs $(56.20 \%)$ reflected average capability in merging their emotions. The table 1 reflects that young adults with fathers doing government jobs (68.20\%), farming $(64.20 \%)$ and private jobs $(57.90 \%)$ were found with poor interpersonal awareness while in case of young adults with mothers doing government jobs (71.40\%) and housewife $(65.30 \%)$ portrayed poor interpersonal awareness and in private jobs category young adults fall in average category (56.30\%). Table 1 also reveals that young adults with government $(68.20 \%)$ and $(52.10 \%)$ private jobs fathers had poor capabilities in intrapersonal awareness while young adults belonging to farmer fathers $(66.70 \%)$ portrayed average capabilities in intrapersonal awareness.

When intelligence of young adults and occupation of parents was compared it was found that young adults belonging to the farmer father $(57.10 \%)$, government job $(50.30 \%)$ and private job $(33.30 \%)$ portrayed poor intelligence. In case of young adult belonging to the mother working in government sector $(67.80 \%)$ and doing household $(44.40 \%)$ were found with poor intelligence while young adults of private job mother portrayed average intelligence $(62.50 \%)$.

It is clearly evident in table 1 that the $p$ value shows that in case of father's occupation, a significant association found in the emotional stress (.03), sense of self (.001), intrapersonal awareness (.001), overall emotional management (.05) and intelligence (.02). While non-significant association was found in the overall mental health, physiological health, daily routine activity, sense of conflictlessness, overall emotional status and interpersonal awareness. Whereas, in case of mother's occupation, there is a significant association found in the overall mental health (.006), sense of self (.01), sense of conflictlessness (.002), intrapersonal awareness (.01) and intelligence (.05). Non-significant association found in the physiological health, daily routine activity, emotional stress, overall emotional status, interpersonal awareness and overall emotional management of young adults.

In conclusion, mental health researches demonstrate that a kind of occupation a family does has a lasting influence their mental health and wellbeing. In light of reports of presents study it can be concluded that the young adults who had farmer father demonstrated poor mental health as compared those with parents doing government and private jobs while the percentage of poor mental health was found higher among respondents who had housewife mothers as compared to respondents with mothers doing government and private jobs. A significant association found between the father's occupation and selected aspects of mental health i.e. emotional stress, sense of self, intrapersonal awareness, overall emotional management and intelligence. Whereas, in case of mother's occupation, a significant association found in the overall mental health, sense of self, sense of conflictlessness, intrapersonal awareness and intelligence. 


\section{Acknowledgments}

This research was supported by Advisory Committee (Dr. Ritu Singh, Associate Professor, HDFS and Dr. Neelam Bhardwaj, Professor and Head, Agricultural Communication) of Ms. Ruchi Singh and Department of Human Development and Family Studies, College of Home Science.

\section{References}

Deswal B.S. and Pawar A. 2012. An Epidemiological Study of Mental Disorders at Pune, Maharashtra. Indian J Community Med, 37(2):116-21. https://en.wikipedia.org/wiki/Occupation

Lok, N., Bademli, K. and Canbaz, M. 2017. Factors Affecting Adolescent Mental Health. Journal of Depression and Anxiety. 6: 283. doi:10.4172/21671044.1000283

Miller, M. 2018, Social \& Emotional Development of Children with Working Parents, Hello Motherhood, https://www.hellomotherhood.com/socialemotional-development-of-children-withworking-parents-8052260.html

Mishra, R. and Gir, S. 2013. Development and Validation of Reproductive Health Knowledge Questionnaire (RH-KQ) for adolescents, Asian Journal of Home Science, 8 (1): 353-355.

Mishra, R. and Gir, S. 2014. Development of case studies to assess impact of family and school on Adolescents Reproductive Health, Indian Research Journal of Genetics and Biotechnology, 6 (3):555559.

Mishra, R. and Gir, S. 2014. Development Psychosocial Stress Questionnaire on Adolescents' Reproductive Health (PSQ-
$\mathrm{RH})$, Indian research journal of Genetics and biotechnology, 6 (3):552-554.

Mishra, R. and Gir, S. 2014. Reproductive Health Attitude Questionnaire (RH-AQ) for adolescents: Development and Validation, International Journal of Family and Home Science, 10 (2): 117120.

Mohsene, L. 2019. The emotional impact of absent parents on children. https://psiloveyou.xyz/the-emotionalimpact-of-absent-parents-on-childrencb013bcbad99

Nair, A. 2018 Impact of Working Parents on Child Development, https://parenting. firstcry.com/articles/impact-of-workingparents-on-child-development/

National Academic Press, 2016. Parenting Matters: Supporting Parents of Children Ages 0-8, https://www.nap.edu/read/ 21868/chapter/3

Singh, L.K. 2018. Impact of Working Mothers on their Children's Development. 3(3) ISSN: 2456-5474. https://www. researchgate.net/publication/331702132_I mpact_of_Working_Mothers_on_their_C hildren's_Development

Singh, R. and Mishra, R., 2020, Mental health of young adults: A descriptive study, International Journal of Education \& Management Studies, 2020, 10(4), 457462

Singh, R. and Mishra, R., 2020. Development and validation of Mental Health Battery (MHB) for young adults, Indian Journal of Health and Well-being 2020, 11(1012), 592-595

WOW Parenting, 2019, Psychological and behavioral effects of both parents working on child https://wowparenting. com/blog/effects-of-working-parents-onchild/

\section{How to cite this article:}

Ruchi Singh and Ragini Mishra. 2021. Parental Occupation and Mental Health of Young Adults. Int.J.Curr.Microbiol.App.Sci. 10(02): 3001-3006. doi: https://doi.org/10.20546/ijcmas.2021.1002.328 